\title{
Frontal EEG asymmetry as predictor of physiological responses to aversive memories
}

Citation for published version (APA):

Meyer, T., Quaedflieg, C. W. E. M., Giesbrecht, T., Meijer, E. H., Abiad, S., \& Smeets, T. (2014). Frontal EEG asymmetry as predictor of physiological responses to aversive memories. Psychophysiology, 51(9), 853-865. https://doi.org/10.1111/psyp.12230

Document status and date:

Published: 30/04/2014

DOI:

10.1111/psyp.12230

Document Version:

Publisher's PDF, also known as Version of record

Document license:

Taverne

Please check the document version of this publication:

- A submitted manuscript is the version of the article upon submission and before peer-review. There can be important differences between the submitted version and the official published version of record.

People interested in the research are advised to contact the author for the final version of the publication, or visit the DOI to the publisher's website.

- The final author version and the galley proof are versions of the publication after peer review.

- The final published version features the final layout of the paper including the volume, issue and page numbers.

Link to publication

\footnotetext{
General rights rights.

- You may freely distribute the URL identifying the publication in the public portal. please follow below link for the End User Agreement:

www.umlib.nl/taverne-license

Take down policy

If you believe that this document breaches copyright please contact us at:

repository@maastrichtuniversity.nl

providing details and we will investigate your claim.
}

Copyright and moral rights for the publications made accessible in the public portal are retained by the authors and/or other copyright owners and it is a condition of accessing publications that users recognise and abide by the legal requirements associated with these

- Users may download and print one copy of any publication from the public portal for the purpose of private study or research.

- You may not further distribute the material or use it for any profit-making activity or commercial gain

If the publication is distributed under the terms of Article $25 \mathrm{fa}$ of the Dutch Copyright Act, indicated by the "Taverne" license above, 


\title{
Frontal EEG asymmetry as predictor of physiological responses to aversive memories
}

\author{
THOMAS MEYER, CONNY W. E. M. QUAEDFLIEG, TIMO GIESBRECHT, EWOUT H. MEIJER, \\ SCHAHRASAD ABIAD, AND TOM SMEETS \\ Faculty of Psychology and Neuroscience, Maastricht University, Maastricht, The Netherlands
}

\begin{abstract}
Evidence suggests that asymmetry in frontal electrical activity predicts responses to aversive experiences, such that higher left-sided activity might dampen responses to trauma reminders. We measured frontal asymmetry at rest and during viewing of a trauma film, and assessed startle responses to film-reminder images. To explore potential moderators, we compared two films (Study 1; $N=64$ ) and modulated reappraisal (Study 2; $N=72$ ). As expected, left frontal activation during film viewing predicted dampened responses in individuals who viewed a staged road accident. However, this effect tended to be reversed when a genocide documentary was used. In Study 2, all participants viewed the genocide film. Left frontal activity at rest again predicted higher startle responses, while reappraisal did not moderate the effects. Thus, the type of trauma film plays a crucial role in the effects of frontal asymmetry, which warrants further critical investigation.
\end{abstract}

Descriptors: Eye-blink startle, Frontal alpha asymmetry, Trauma film, Aversive memories, Post-traumatic stress disorder

A considerable proportion of the general population is exposed to highly aversive events, such as rape, abduction, severe accidents, or disasters, at least once in their lifetime (Ozer, Best, Lipsey, \& Weiss, 2003). Despite the deep emotional impact of such experiences, most individuals display successful psychological adjustment, or so-called resilience (Bonanno, 2004). However, there seem to be large individual differences in how well people can adjust to such experiences. That is, some victims develop debilitating symptoms following aversive experiences, such as highly distressing memory intrusions and exaggerated startle responses (Brewin, Gregory, Lipton, \& Burgess, 2010; Orr \& Roth, 2000). Thus, an intriguing question that arises is which individual characteristics may be responsible for resilience, and thus offer protection from such symptoms.

The present article focuses on so-called frontal asymmetry as a marker of resilience, and explores its potential role in responding to adversity by using an analog trauma film paradigm (Holmes \& Bourne, 2008) in healthy participants. Frontal asymmetry has been studied extensively in individual differences research on emotion and refers to the average difference in alpha-band activity between the left and right frontal areas across several minutes, measured

This study was supported in part by Grant 056-25-011 from the Netherlands Organization for Scientific Research (NWO) to Dr. Tom Smeets. Parts of these data have been presented at the 13th ESTSS conference in Bologna, Italy. We are especially thankful to Sarah Baumann, Saira Berberovic, Hans Keulers, Sarah Mauder, Andrea Nagel, Ingrid Rooijakkers, and Maxi Volk for their help in collecting the data for Study 1.

Address correspondence to: Thomas Meyer, Faculty of Psychology and Neuroscience, Maastricht University, P.O. Box 616, 6200 MD Maastricht, The Netherlands. E-mail: thomas.meyer@maastrichtuniversity.nl with electroencephalography (EEG; Harmon-Jones, Gable, \& Peterson, 2010). Based on the assumption that alpha band power is inversely related to brain activity (Pfurtscheller, Stancak, \& Neuper, 1996), frontal asymmetry is widely assumed to reflect hemispheric differences in frontal brain idling or activity. Given its excellent internal consistency and reasonable test-retest reliability ranging from 0.5 to 0.6 across several weeks (Tomarken, Davidson, Wheeler, \& Kinney, 1992; Towers \& Allen, 2009), frontal asymmetry has been studied as a trait marker of individual differences. Most commonly, it is measured while participants are at rest, whereby it purportedly taps into stable individual differences of resting brain activity. More recently, several studies additionally measured frontal asymmetry during an emotional provocation (e.g., Goodman, Rietschel, Lo, Costanzo, \& Hatfield, 2013), following the argumentation that asymmetric activation during challenge more reliably taps into an individual's traitlike capability of emotional responding, compared with resting frontal asymmetry (Coan, Allen, \& McKnight, 2006).

Although its neuroanatomical and psychological links with mental health and emotional responding are still poorly understood (Allen \& Kline, 2004; see also Miller, Crocker, Spielberg, Infantolino, \& Heller, 2013), frontal asymmetry is thought to have broad implications for emotional experience and well-being. It has been described as an index of an individual's traitlike style of affective responding by reflecting the relative activity of lateralized brain systems subserving motivation (Davidson, 1998) or emotional valence (Heller, 1993). In line with this view, it has repeatedly been found to predict emotional and behavioral reactions to stressful situations, as well as the presence of psychopathology. For instance, more left-sided frontal activity at rest has been linked to 
superior affect and stress regulation (e.g., Koslov, Mendes, Pajtas, \& Pizzagalli, 2011; Tomarken, Davidson, Wheeler, \& Doss, 1992), lower levels of anxiety and depression (Thibodeau, Jorgensen, \& Kim, 2006), and lower risk of developing depression (Nusslock et al., 2011). Furthermore, left-sided frontal activation during a sad film, but not resting frontal asymmetry, was recently found to predict dampened effects of adverse life events on psychopathology in a prospective study (Lopez-Duran, Nusslock, George, \& Kovacs, 2012), which also emphasizes the merit of measuring frontal asymmetry in different conditions. Based on these observations, it is conceivable that more left-sided frontal activity at rest and during provocation can predict adaptive responding to aversive experiences.

Interestingly, Jackson et al. (2003) found a link between more left-sided frontal activity at rest and enhanced downregulation of physiological responses to aversive stimuli. In particular, these authors used a sophisticated startle paradigm in which startle probes were administered both during and shortly after picture presentation. This enabled them to assess the chronometry of startle responding, which is thought to be driven by amygdala activation during confrontation with fear-associated stimuli (Davis, Walker, \& Lee, 1997). Therefore, in Jackson et al.'s experiment, startle responses after elicitor offset were of particular interest for emotion regulation. These startle responses index sustained affective processing, which is thought to be inversely related to the rapidity with which prefrontal structures downregulate the amygdala to instantiate affective recovery (Goldsmith \& Davidson, 2004). Strikingly, Jackson et al. (2003) found that left-sided frontal activity at rest specifically predicted lower startle response magnitude after negative picture offset, indicating enhanced affective recovery. Partly corroborating these findings, Goodman et al. (2013) more recently showed that left-sided activity during a threat provocation, but not at rest, predicted attenuated startle responses. Further support for the involvement of frontal asymmetry in affect regulation stems from research showing that left-sided frontal activation has been observed during cognitive reappraisal (Parvaz, MacNamara, Goldstein, \& Hajcak, 2012). This emotion regulation strategy implies deliberately altering a situation's emotional impact by changing its interpretation (Gross \& John, 2003), which is negatively associated with the severity of trauma-related symptoms (Boden et al., 2013) and is considered effective in reducing physiological responding (Gross \& John, 2003). Taken together, the available evidence shows that individual differences in frontal asymmetry at rest and during provocation can inform about physiological response regulation after aversive stimulation.

\section{Aims and Outline of the Present Studies}

While the above-mentioned studies suggest an intimate involvement of frontal asymmetry in resilience, it is not clear whether it is also implicated in more specific processes relevant to the adjustment after aversive experiences. For instance, it has not yet been investigated whether this marker is related to affective responses to aversive memories. Memory-related affect regulation is crucial in the adjustment to adversity, since trauma victims often suffer from physiological hyperarousal when confronted with stimuli that remind them of their traumatic experience (Orr \& Roth, 2000). Thus, our first aim was to test the idea that more left-sided frontal activity would predict enhanced emotion regulation when individuals are confronted with stimuli that remind them of aversive experiences. Following the findings of Jackson et al. (2003), we expected frontal asymmetry to predict downregulation of startle responses. Therefore, we conducted two independent studies in which we measured frontal asymmetry at rest in healthy participants, who were then subjected to an analog trauma film paradigm (Holmes \& Bourne, 2008). While participants viewed a shocking film, asymmetric frontal activation with respect to baseline was also measured, and was included as an additional predictor of later physiological responses during memory activation. These changes in asymmetric frontal activation can be expected to be equally or perhaps even more predictive of later physiological responses than the resting asymmetry index. On the one hand, provocationinduced asymmetries might tap more reliably into individual differences, in line with the capability model (Coan et al., 2006). On the other hand, activation asymmetry during film viewing might mediate (mal)adaptive emotional responding leading to exaggerated startle (Coan \& Allen, 2004). Next, participants underwent an eye-blink startle paradigm (Jackson et al., 2003) to assess physiological responses during and after presentation of images that elicited memories of the previously seen aversive film, compared to unrelated images.

The second aim of the present studies was to assess how robust possible relations between frontal asymmetry and physiological responses to reminder stimuli are across different contexts. That is, just as other risk and resilience factors (e.g., McNally \& Robinaugh, 2011), frontal asymmetry may not display universal effects in responding to adversity, but could depend on additional situational factors. For instance, we recently found that habitual use of cognitive reappraisal predicted dampened affective responses to a fear-inducing film, but only in those individuals who were already familiar with the film (Meyer, Smeets, Giesbrecht, \& Merckelbach, 2012). Similarly, frontal asymmetry may help to reduce physiological responses to film-related memories only under favorable circumstances, for example, when the content and context of the film permits or encourages reappraising it in a benign manner. Therefore, we tested our main hypotheses in two different types of trauma film (Study 1) and within a single trauma film that was followed by provision of positive and negative contextual information (Study 2).

In both studies, we hypothesized that frontal asymmetry, both at rest and during film viewing, would be predictive of physiological self-regulation in response to reminder images, irrespective of condition effects. In particular, more left-sided frontal activity was expected to predict dampened startle responses shortly after reminder picture offset. Additionally, we tested moderation by different conditions, speculating that the expected effects of frontal activity would be more pronounced when the trauma film can easily be interpreted in a benign manner (Study 1), and when participants receive positive rather than negative contextual information about a trauma film (Study 2).

\section{Study 1}

In this study, we first measured resting frontal asymmetry, and had participants then view one of two different films, while all of them afterwards viewed reminder images from both films in a startle paradigm. One film consisted of real-life footage from a documentary about the 1994 Rwandan genocide, whereas the other is a staged educational movie depicting a severe road accident. Parts of both films, as well as films with similar content (see Weidmann, Conradi, Grögera, Fehma, \& Fydrich, 2009), have been used frequently in trauma film studies, where they successfully induced negative emotion, involuntary memories, and exaggerated startle responses upon presentation of reminder pictures (e.g., Holmes, 


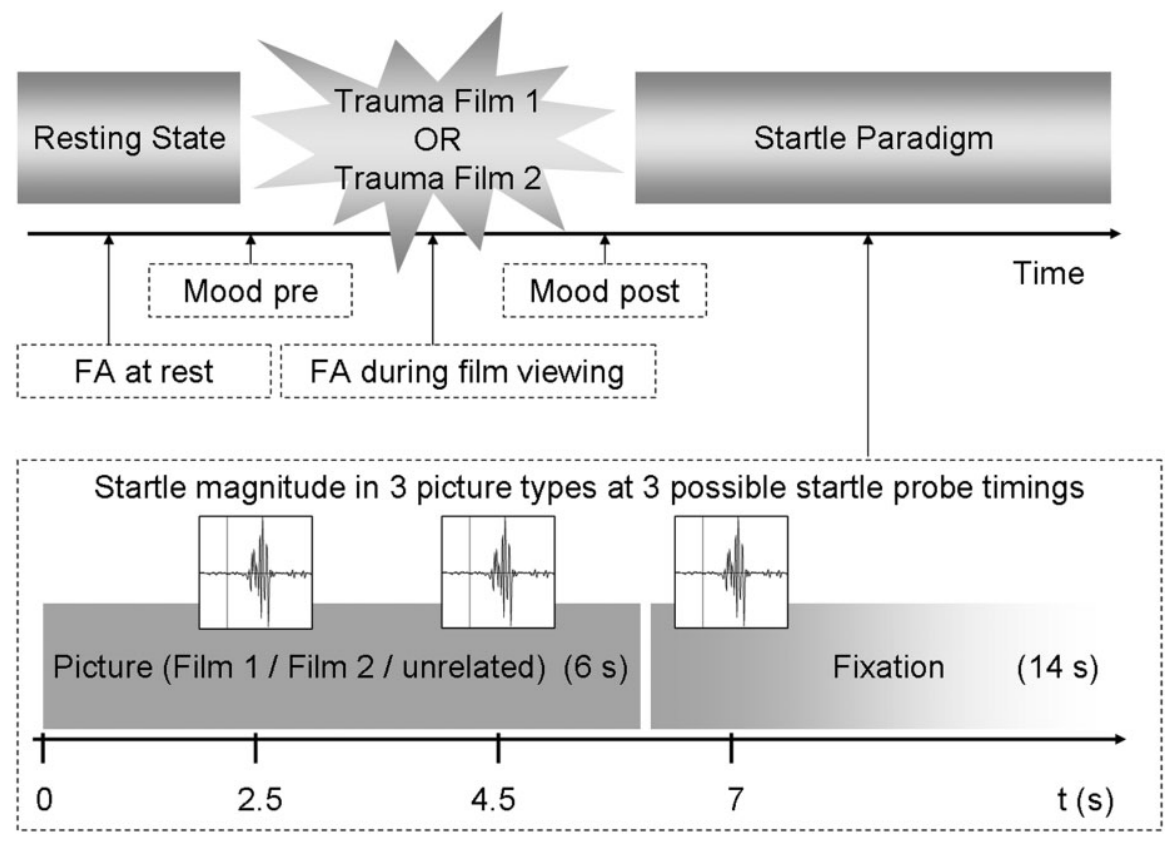

Figure 1. Timeline of Study 1. Above the timeline, the order in which the tasks were administered is displayed. Below the timeline, the essential measures used in the analyses, as well as the general trial procedure of the eye-blink startle paradigm, are summarized. FA = frontal alpha asymmetry.

James, Coode-Bate, \& Deeprose, 2009; Meyer et al., 2013). Thus, both films are well suited for our purpose. Their traumatic content clearly differs, which allows exploring the robustness of frontal asymmetry effects across trauma film types. In particular, the road accident film may be easier to interpret in a positive and meaningful way since it is staged (e.g., "No one was really harmed") and has a more positive educational message (e.g., "Road accidents can be prevented"), compared to the genocide documentary. If such differences play a moderating role, one might expect more pronounced effects of frontal asymmetry on physiological responding to reminder stimuli in the road accident condition.

\section{Method}

Participants. Sixty-five healthy young undergraduates were recruited via advertisements at the university campus and received partial course credit or a small financial compensation in return for their participation. Individuals who responded to the advertisements were screened for eligibility using the following exclusion criteria: (a) recent psychological complaints, (b) drug or alcohol abuse or addiction, (c) medical conditions or medication that could affect physiological recordings, (d) high self-relevance of filmrelated stimuli including blood phobia, current pregnancy, and a history of a severe accident, assault, or injury, and (e) dominant left-handedness. All participants had normal or corrected-tonormal vision, and in the latter case were asked to wear glasses instead of contact lenses to reduce blinking artifacts. One participant did not complete the experiment following technical failure and was excluded from all analyses. The remaining 64 (46 women) had a mean age of 20.6 years $(S D=2.3$; range: $18-29)$. All participants provided written informed consent. The study was approved by the standing ethical committee of the Faculty of Psychology and Neuroscience, Maastricht University.

Procedure. Participants were invited for a single laboratory session that was scheduled in the afternoon to reduce time-of-day effects on frontal asymmetry (Velo, Stewart, Hasler, Towers, \& Allen, 2012). Beforehand, they were instructed by e-mail to refrain from drugs (including alcohol) for $24 \mathrm{~h}$, and from heavy physical activities, smoking, and drinking coffee for $1 \mathrm{~h}$ prior to participation. Participants were seated in a soundproof, electrically shielded testing room, in front of a 22-inch widescreen monitor (Philips, the Netherlands) at approximately $56 \mathrm{~cm}$ unrestrained viewing distance. They first completed questionnaires. Next, and after preparing the skin with abrasive gel, electrodes for electromyogram (EMG), electrooculogram (EOG), and EEG recordings were prepared. Participants were shown the raw recording signals to demonstrate common artifacts that occur with open and closed eyes due to body and eye movements, followed by measuring resting-state EEG. Subsequently, participants were randomly assigned to watch one of two trauma films and were instructed to imagine being a witness to these scenes. Before and after the trauma film, mood was assessed with questionnaires. Participants then underwent an eye-blink startle paradigm with the instruction to watch a series of pictures, some of which would be film related, attentively (i.e., without looking away or closing the eyes, and in such a way that they would know exactly what was shown in the picture). At the end of the session, the electrodes were removed, and participants received financial or course credit compensation for their efforts and were fully debriefed by e-mail. Figure 1 displays the timeline of this study.

\section{Materials and tasks}

Questionnaires. The state version of the Positive and Negative Affect Schedule (PANAS; Watson, Clark, \& Tellegen, 1988) was administered to measure pre- and postfilm positive affect ( $\alpha s>.78$ ) and negative affect ( $\alpha s>$.76). Additionally, visual analogue scales (VAS) were used to measure changes in the current degree of feeling fearful, shocked, sad, and angry, ranging from $0=$ not at all to $100=$ very much . Furthermore, we included questionnaires at baseline and concerning dissociative responses to film viewing that are not addressed here. All questionnaires were computer administered. 
Trauma films. Two trauma film fragments, each lasting approximately $14 \mathrm{~min}$, were used. The first is a compilation of a documentary about the 1994 Rwandan genocide ("Ghosts of Rwanda"; Artwork PBS, 2004), consisting of real-life footage of death and mutilation with voice-over outlining background and extent of the events, next to interviews with affected individuals. The second film is a compilation of a road education movie co-produced by Gwent Police (http://www.gwent.police.uk), depicting a severe road accident, including the events leading up to it and its aftermath. In short, three young girls, one of whom is pregnant, become involved in an accident after arguing about a text message that the driver wants to send while driving. The accident causes severe injuries and even fatalities, and is followed by a dramatic rescue operation, all of which is shown in full detail.

Resting EEG recording. Similar to the procedure of Tomarken, Davidson, Wheeler, and Kinney (1992), the restingstate task consisted of eight 1-min blocks, half with eyes open and half with eyes closed. The beginning of each block was signaled by a single tone, and the end of each block was signaled by a double tone. Between blocks, instructions to close or open the eyes in the next block appeared for $20 \mathrm{~s}$. The order of conditions was randomized for each participant, whereby each condition was repeated no more than twice in a row.

Eye-blink startle paradigm. Ninety different images served as stimuli in the startle paradigm (Jackson et al., 2003; Meyer et al., 2013). Pictures belonged to one of three categories: 30 reminder pictures from each of the two trauma film fragments, next to 30 neutral control (medium valence, low arousal ratings) pictures from the International Affective Picture System (IAPS; Lang, Bradley, \& Cuthbert, 2005). Reminder pictures were screen captures from the two fragments that contained no graphically disturbing details (i.e., the reminder pictures were chosen to be as neutral as possible). Since the trauma films differed strongly from each other visually and conceptually, reminder images of the unseen film were very unlikely to activate memories of the seen film.

As displayed in Figure 1, lower panel, each trial consisted of a picture that was shown for $6 \mathrm{~s}$, followed by an intertrial interval of $14 \mathrm{~s}$. This picture was accompanied by a 50 -ms white noise startle probe (near-instantaneous rise time) presented via headphones. Intensity of the probes was set at $90 \mathrm{~dB}$. Probe onset occurred at $2.5 \mathrm{~s}, 4.5 \mathrm{~s}$, or $7 \mathrm{~s}$ relative to stimulus onset, with each timing occurring in 30 trials. The trial sequence was randomized with no more than three consecutive trials having the same probe onset or picture category. To reduce the predictability of startle probes, six trials without startle probe were inserted into the trial sequence (two from each picture category). Three pauses were inserted to avoid fatigue.

Physiological recordings. Following published guidelines (Keil et al., 2013; Pivik et al., 1993), EEG was measured with $\mathrm{Ag} / \mathrm{AgCl}$ electrodes in an electrode cap positioned according to the International 10-20 system (American Electroencephalographic Society, 1994), including the channels FZ, F3, F4, F7, F8, FC3, FC4, CZ, P3, P4, P7, P8, and A2, and using a BrainAmp EEG amplifier (Brain Products $\mathrm{GmbH}$, Germany). Signals were sampled continuously at $1000 \mathrm{~Hz}$, referenced online to the left mastoid (A1), bandpass filtered $(0.1-35 \mathrm{~Hz})$, and stored. An electrode at AFz served as signal ground. EOG electrodes were applied above and below the right eye for vertical, and at the outer canthus of each eye for horizontal eye movement recording. Simultaneously, following the guidelines by Blumenthal et al. (2005), EMG from the orbicularis oculi muscle was continuously sampled at $1000 \mathrm{~Hz}(0.1-499 \mathrm{~Hz}$ band-pass filtered), using two $\mathrm{Ag} / \mathrm{AgCl}$ electrodes below the participant's left eye. All electrode impedances were kept below $5 \mathrm{kOhm}$ with homologous scalp electrodes being within $1 \mathrm{kOhm}$ of each other.

\section{Data reduction}

EEG asymmetry scores. Consistent with data reduction procedures in previous frontal asymmetry studies (for a review, see Allen, Coan, \& Nazarian, 2004), EEG data were rereferenced offline to the average of A1 and A2 and band-pass filtered from 1 to $30 \mathrm{~Hz}$. To derive resting-state frontal asymmetry scores, each 1-min block was divided in 2-s epochs (75\% overlap). Epochs were defined as artifact contaminated (e.g., by eye movement or muscle activity) and removed when vertical EOG or EEG activity exceeded thresholds of \pm 200 and $\pm 75 \mu \mathrm{V}$, respectively. Data from one participant (road accident condition) were excluded because only $8 \%$ of epochs in the eyes-open condition were artifact free. For all other participants, on average $78.9 \%$ (range $=$ $43-100 ; S D=17.2$ ) of eyes-open and $96.7 \%$ (range $=60-100$; $S D=7.4$ ) of eyes-closed epochs were artifact free. Power density for each retained epoch was derived by fast Fourier transformation (FFT) using a 100\% Hanning window. Average power densities were calculated separately for the eyes-open and eyesclosed conditions and weighted for the number of artifact-free epochs. Log-transformed alpha-power density $(8-13 \mathrm{~Hz})$ values were used to calculate asymmetry scores (i.e., $\ln [$ right $]-\ln [$ left]), that were then averaged across eyes-open and eyes-closed conditions.

For our analyses, we concentrate on alpha power asymmetry in the widely used midfrontal leads (F4, F3), and on the midline frontocentral leads (FC4, FC3), for which sites Jackson and colleagues (2003) demonstrated a relationship with startle responding. Since we did not have separate hypotheses for frontal and frontocentral asymmetries and in order to reduce the number of statistical analyses (and consequently the probability of Type 1 error), we used a composite frontal asymmetry index (mean of $\ln [\mathrm{F} 4], \ln [\mathrm{FC} 4]$ - mean of $\ln [\mathrm{F} 3], \ln [\mathrm{FC} 3])$. For one participant (road accident condition), frontal asymmetry could not be determined due to corrupted recordings in one of the frontal channels.

In order to obtain activation asymmetry scores, frontal asymmetry during film viewing was computed similarly to resting state asymmetry. Continuous recordings (approximately $14 \mathrm{~min}$ ) were divided in 2-s epochs (75\% overlap) to derive frontal asymmetry scores at the frontocentral leads. Data from 5 participants ( 3 from the road accident condition) for whom less than $25 \%$ artifact-free epochs could be retained were excluded from these analyses. For all other participants, on average $66.2 \%$ (range $=25-98$; $S D=19.8)$ of all epochs $(N=1,658)$ were artifact free. This percentage did not differ between the film conditions, $t(57)=.72$, $p=.47$. Activation asymmetry scores were derived by subtracting resting-state asymmetry from frontal asymmetry scores during film viewing. Finally, data were available from 62 participants $(30$ in the road accident condition) for analyses of resting frontal asymmetry, and from 58 participants ( 28 in the road accident condition) for analyses involving frontal activation asymmetry.

Startle responses. Calculation of startle responses followed the recommendations by Blumenthal et al. (2005). EMG signals were converted into a bipolar channel, $28 \mathrm{~Hz}$ high-pass filtered, rectified, 
and smoothed using a $40 \mathrm{~Hz}$ low-pass filter. For each trial, EMG signals were extracted from $-50 \mathrm{~ms}$ to $250 \mathrm{~ms}$ relative to startle probe onset. The period from $-50 \mathrm{~ms}$ to probe onset was used for baseline correction and was inspected semiautomatically for artifacts (e.g., EMG or vertical EOG exceeding a threshold of $\pm 20 \mu \mathrm{V}$ or $\pm 200 \mu \mathrm{V}$, respectively, or reflex onset before probe onset). By means of the EMG onset search algorithm implemented in Vision Analyzer 2.0 (Brain Vision), reflex onset was extracted automatically between 20 and $120 \mathrm{~ms}$ after probe onset (criterion: 4 SD with respect to baseline), as well as the peak value following onset, followed by a visual check of the onset search. This yielded a startle magnitude per trial (peak minus onset values). Trials without eye-blink response were rated as zero. Data from 3 participants (1 in the road accident condition) had to be excluded because onsets and peaks could not be determined in a majority of responses. Startle magnitudes deviating more than $3 S D$ from the individual's mean were replaced by the mean $\pm 3 S D$ to treat extreme values (i.e., Winsorizing; see Rivest, 1994). Magnitudes were then square root-transformed and averaged within subjects for each stimulus category and startle probe time, respectively. Startle potentiation scores (i.e., mean magnitude on film trials minus mean magnitude on neutral trials) were calculated per probe time, separately for seen film and not-seen film probes.

Statistical analysis. Single extreme scores in the distributions of EEG asymmetry and startle potentiation were replaced so that their deviance from the sample mean equaled 2.5 times the sample $S D$ (Rivest, 1994). Next, in order to reduce their right-skewed distributions, PANAS-negative affect and negative emotion VAS scores were log-transformed prior to the analyses. For better readability, uncorrected descriptive statistics are reported. Effects of the interventions on frontal asymmetry, current emotion, and startle potentiation were addressed using repeated measures analyses of variance (ANOVAs) and $t$ tests. The main hypotheses were addressed using multiple linear regression and correlation analyses, with seen-film startle potentiation after picture offset (i.e., at the 7-s probe timing) scores as dependent, and frontal asymmetry scores as independent variables. To assess possible interactions with film condition, this between-subjects factor was entered in all analyses. In the regression models, film condition (dummy variable) and interaction terms of frontal asymmetry by film condition (i.e., $z$ transformed asymmetry scores $\times$ film condition dummy) were thus entered as predictors. To assess the specificity of effects, we also explored whether frontal asymmetry also predicted startle potentiation during picture viewing (i.e., at the 2.5- and 4.5-s timing) and whether parietal alpha asymmetry (at $\mathrm{P} 4 / \mathrm{P} 3$ ) predicted startle potentiation after picture offset. When sphericity assumptions for ANOVAs were violated, Greenhouse-Geisser corrected $p$ values, along with the respective epsilon and uncorrected degrees of freedom, are reported. Alpha was set at .05 (two-tailed) for all analyses.

In our main analyses, resting frontal asymmetry is modeled as a moderator between affective responding to film viewing and startle potentiation (see Figure 2, panel A). Frontal activation asymmetry, however, may both moderate and mediate the effects of film viewing on startle responses. In order to assess the plausibility of a mediation model (see panel B), we tested whether film viewing systematically changed asymmetry scores. Furthermore, we explored whether this change corresponds to the subjective intensity of responding to the film. Finally, in order to elucidate the interdependence of trait and state frontal asymmetry in the current study, we report correlations between these indices.

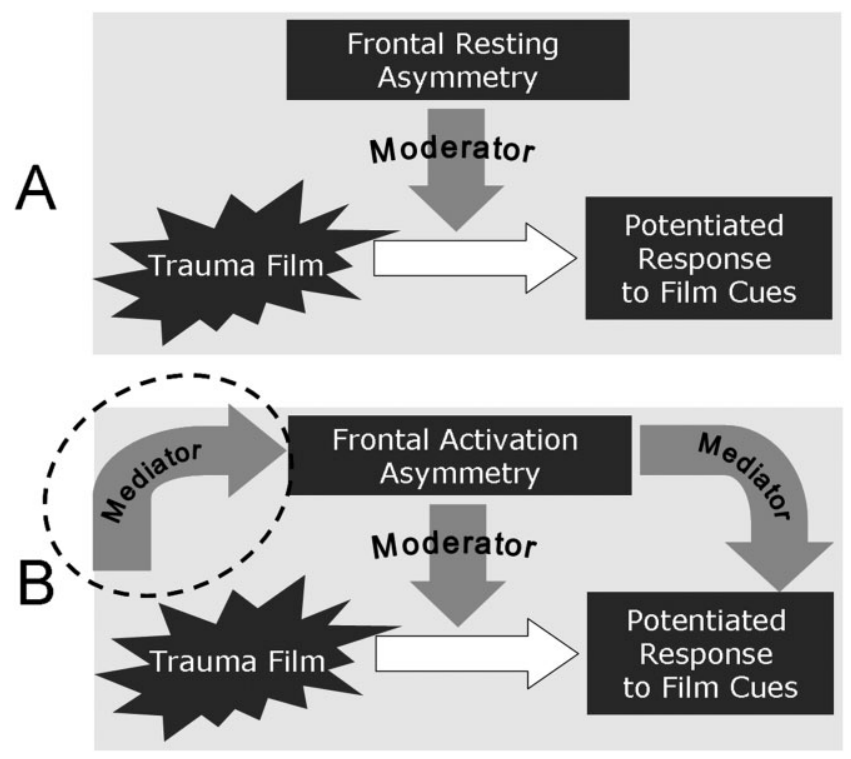

Figure 2. Theoretical models linking frontal asymmetries and startle responses. A: Potential involvement of resting frontal asymmetry as a moderator of potentiated startle responses following film viewing. B: Potential involvement of activation asymmetries during film viewing. Similarly to resting asymmetry, they might act as a moderators, but could as well reflect (mal)adaptive responses that mediate later effects on startle. All models predict statistical associations between asymmetry and physiological responses. However, only the mediation model additionally predicts an association between trauma film responding and activation asymmetry, as highlighted by the dashed circle.

\section{Results}

Resting and activation asymmetries. A repeated measures ANOVA showed no difference between resting and film-viewing frontal asymmetries, and no effects involving film condition, all $p s>.17$. Further at odds with a mediation model (Figure 2, panel B), frontal activation asymmetry did not correlate with any PANAS or VAS change score, all $r \mathrm{~s}(58)<.20, p>.13$, which was not moderated by the type of film that had been seen, all interaction $p$ s > .11. In line with previous studies (e.g., Goodman et al., 2013), resting frontal asymmetry scores $(M=0.06, S D=0.12)$ correlated positively with asymmetry during film viewing $(M=0.05$, $S D=0.14), r=.85, p<.001$, but no correlation with frontal activation asymmetries emerged $(M=0, S D=0.08), r=.04, p=.75$. Figure 3 displays the raw power density across frequencies from which alpha asymmetry scores were derived, as a function of condition.

Emotional responses. The two film conditions did not differ at baseline on any PANAS or emotion VAS subscale, all $t \mathrm{~s}(62)<1.2$, $p s>.25$. For positive affect, a 2 (Time: pre, post) $\times 2$ (Film Condition: genocide, road accident) repeated measures ANOVA revealed a significant main effect of time, $F(1,62)=5.3, p=.025$, $\eta_{\mathrm{p}}^{2}=.08$, with positive affect decreasing by 1.5 points $(S D=5.3)$ in response to film viewing, in the absence of main or interaction effects involving film condition, $F \mathrm{~s}<1, p \mathrm{~s}>.82$. For negative affect, a significant time effect was revealed, $F(1,62)=80.5$, $p<.001, \eta_{\mathrm{p}}^{2}=.57$, but also a significant interaction with film condition emerged, $F(1,62)=20.7, p<.001, \eta_{\mathrm{p}}^{2}=.25$. An independent samples $t$ test on negative affect change scores showed a stronger 


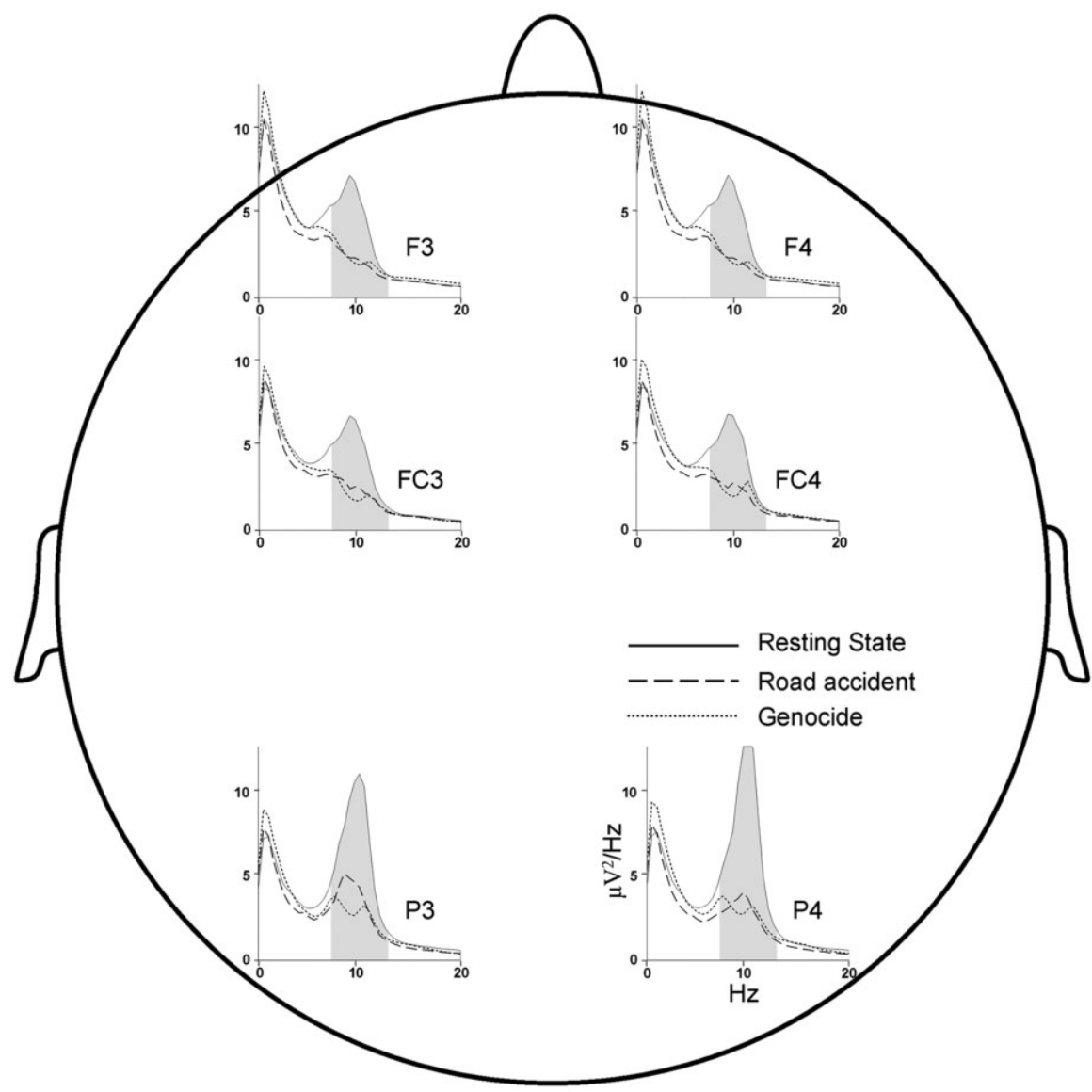

Figure 3. Topographical display of power density as a function of condition. The lines represent average power densities across frequencies at rest (solid lines; collapsed across conditions) and during film viewing (dashed lines), separately for the road accident $(n=28)$ and during the genocide film condition $(n=30)$. The gray area marks the alpha band, in which power densities were averaged to derive alpha asymmetry scores.

increase in the genocide condition (Mean change $=8.8, S D=5.2)$ than in the road accident condition (Mean change $=2.3, S D=4.8$ ), $t(62)=4.5, p<.001$.

For the negative emotion VAS items, a 4 (Emotion) $\times 2$ (Time) $\times 2$ (Film Condition) repeated measures ANOVA revealed a significant three-way interaction, $F(3,186)=5.7, \varepsilon=.79, p=.002$, $\eta_{\mathrm{p}}^{2}=.08$. Paired samples $t$ tests in the two film conditions showed no significant increase in fearfulness for both the genocide and the road accident condition, $p s>.16$. The other three emotions (shocked, sad, angry) increased significantly in both conditions, with all $t \mathrm{~s}(31)>3.4$, all $p \mathrm{~s}<.01$ (see Figure 4). Independent samples $t$ tests showed that the increases in feeling shocked and angry were larger in the genocide condition (Mean change $_{\text {being }} 50.8$ and 42.1 , respectively, $S D=32.5,32.5$ ) compared with the road accident condition (Mean change $_{\text {being }}$ 25.3, 8.8, respectively, $S D=27.2,21.6), t \mathrm{~s}(62)>2.6, p<.02$. No differences were evident for anxiety and sadness change, $t \mathrm{~s}(62)<1.3, p \mathrm{~s}>.20$.

Condition effects on time course of startle potentiation. A 2 (Category: seen, unseen) $\times 3$ (Timing) $\times 2$ (Film Condition) repeated measures ANOVA on startle potentiation scores revealed no significant main or interaction effects of category, timing, or film condition (all $p \mathrm{~s}>.25$ ), except for a significant Category $\times$ Film Condition interaction, $F(1,59)=5.3, \quad p=.03, \quad \eta_{\mathrm{p}}^{2}=.08$. Follow-up repeated measures ANOVAs per film condition showed a main effect of category in the genocide film condition,
$F(1,29)=4.2, p=.05, \eta_{\mathrm{p}}^{2}=.13$, with seen-film potentiation scores being higher than unseen-film scores, which effect was not evidenced in the road accident condition, $F(1,30)=1.5, p=.24$, $\eta_{\mathrm{p}}^{2}=.05$

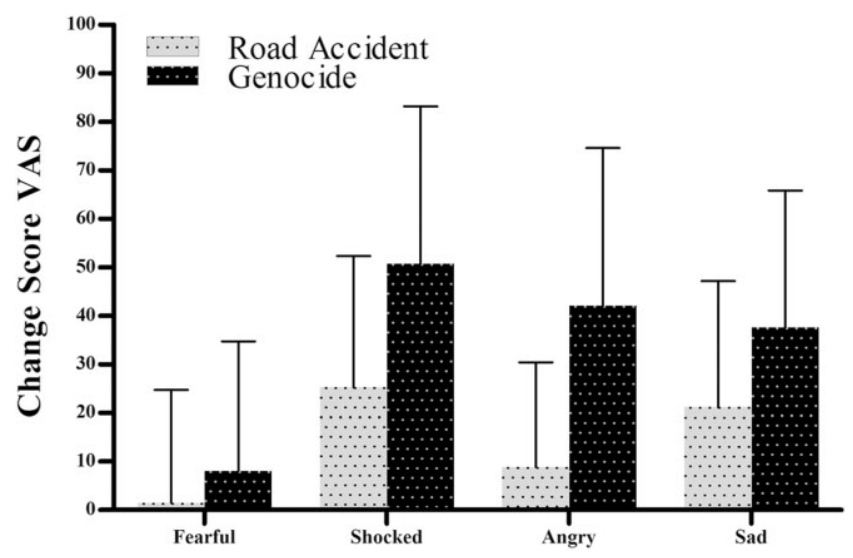

Figure 4. Specific negative emotion changes in response to film viewing on $100-\mathrm{mm}$ VAS. $N=32$ in each film condition. Error bars indicate standard deviations. 


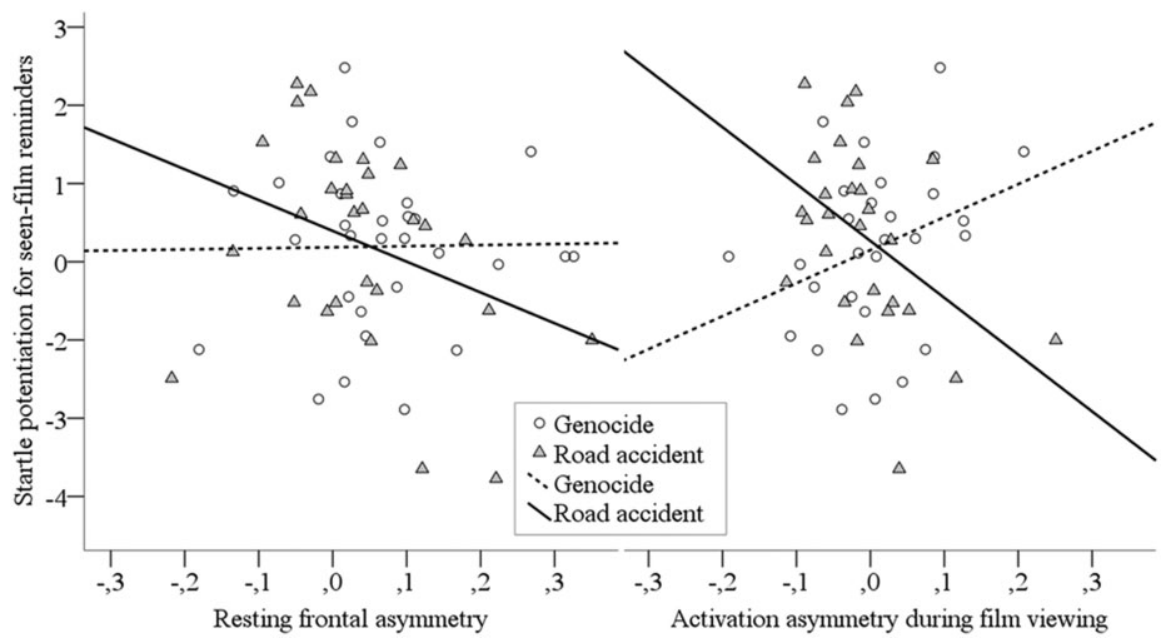

Figure 5. Scatter plots depicting frontal asymmetry at rest (left; $N=59$ ) and activation asymmetry during film viewing (right; $N=55)$ as predictors of startle potentiation at $7 \mathrm{~s}(1-\mathrm{s}$ poststimulus offset) for seen-film reminders. The interaction with film condition is significant for activation asymmetry, where a significant negative correlation emerged for the road accident condition only.

Frontal asymmetry effects on startle potentiation ${ }^{1}$. We first ran regression models to explore interactive effects of frontal asymmetry and film condition on startle potentiation after seen-film picture offset (i.e., at the 7-s probe timing, measuring emotion regulation). For resting frontal asymmetry $(d f=3,55)$, the interaction term was not significant, $p=.13$. In the entire sample, resting frontal asymmetry did not correlate significantly with startle potentiation after reminder picture offset, $r(59)=-.18, p=.17$. In the models using frontal activation asymmetry as a predictor $(d f=3,51)$, the interaction term was a significant predictor, $\beta=.54, t=3.1, p=.003$. Therefore, we performed correlation analyses separately for the two film conditions. In the road accident condition, left-sided frontal activation correlated significantly and negatively with startle potentiation, $r(27)=-.47, p=.014$. In contrast, in the genocide condition, a positive trend emerged, $r(28)=.32, p=.095$ (see Figure 5).

For comparison, parietal resting and activation asymmetries (sites P4/P3) did not display any interaction effects with film condition on seen-film startle potentiation, $p s>.40$, and there were also no significant correlations in the entire sample, $p s>.41$. To assess the specificity of frontal asymmetry effects on startle potentiation after picture offset, we also looked at interaction and main effects for startle probes during picture presentation. This revealed no additional interaction effects for resting frontal asymmetry and also no significant correlations in the entire sample, all $p s>.47$. However, for activation asymmetry, there was a significant interaction with film condition at the 2.5 -s probe, $\beta=.39, t=2.2$, $p=.033$. Although no significant correlations between frontal activation asymmetry and startle potentiation emerged in either of the film conditions, the pattern was similar to the 7-s probe timings, with negative correlation coefficients in the road accident condition, $r(27)=-.29, p=.14$, and positive coefficients in the genocide condition $r(28)=.30, p=.12$, which accounted for the significant interaction.

1. None of the PANAS and emotion VAS change scores correlated significantly with any of the startle potentiation scores for seen-film trials, all $r \mathrm{~s}<.22, p \mathrm{~s}>.09$. Therefore, we did not consider these variables as additional predictors in the following analyses.

\section{Summary}

Resting frontal asymmetry was not predictive of physiological responding to trauma film reminders in Study 1, while our results indicate that the effect of film-related activation asymmetry was moderated by film condition. Thus, our findings do not support the idea that frontal asymmetry predicts physiological responding to emotional memories in a straightforward manner. We found the predicted association between more left-sided frontal activation with enhanced physiological self-regulation in reminders (i.e., dampened startle after picture offset), but only in the road accident condition. Meanwhile, a dissimilar effect was found in participants who saw the genocide film. Here, contrary to expectations, leftsided frontal activation not only appeared to have less dampening effects on startle, but we even observed a (nonsignificant) positive correlation with startle after picture offset. Thus, the two film conditions were apparently characterized by effects that clearly differed in size, and possibly also in direction. This suggests differences in emotion regulatory processes between the two film conditions. Speculatively, the road accident film may have been easier to reappraise in a benign manner, and to integrate with existing schemas, than the genocide film. An explanation for our findings might be that the effects of frontal asymmetry on physiological self-regulation depend on circumstances that facilitate cognitive emotion regulation. Study 2 aimed to further explore this possibility by showing the genocide film and making positive reappraisal either easier or more difficult by providing additional written information about the film.

\section{Study 2}

Study 2 builds on the findings from Study 1. We now tested the hypothesis that the findings in Study 1 were due to the ease with which participants engaged in cognitive reappraisal. In particular, we hypothesized that facilitating positive reappraisal after viewing the genocide film, where reappraisal is purportedly more difficult to apply, would change the effects of frontal asymmetry on physiological responses to reminder stimuli. Therefore, this study was similar in design to Study 1, yet all participants were exposed to the genocide film, and only pictures from the genocide film were used 
as reminders in the startle paradigm. Furthermore, participants were provided with written information about the film that either encourages positive reappraisal or emphasizes negative aspects of the film. We measured engagement in positive reappraisal using an adapted state questionnaire. In the positive condition, we thus expected higher left-sided frontal activity to correlate with dampened startle potentiation after reminder picture offset, just as we found in the road accident condition in Study 1. Based on the findings in Study 1, we expected no or an opposite correlation in the negative condition.

In addition to reminder and neutral control pictures, we inserted unrelated negative pictures as a category to the startle paradigm. This was done to compare the effect of frontal asymmetry on responding to film reminders to its effect on responding to immediate affective provocation. Thus, similar to the findings of Jackson et al. (2003), we expected more left-sided frontal activity to predict dampened startle potentiation after unrelated negative image offset.

\section{Method}

Participants. Seventy-two healthy students (55 women) with a mean age of 20.9 years $(S D=2.1$; range: $18-30)$ participated in the experiment. Recruitment procedures, inclusion criteria, and compensation for participation were identical to Study 1. The study was approved by the standing ethical committee of the Faculty of Psychology and Neuroscience, Maastricht University.

Procedure. The procedure was kept similar to Study 1. All state and trait questionnaires used in Study 1 were included, and physiological recordings were identical. Again, not all questionnaire data are presented here. After completion of baseline questionnaires and EEG measurements, all participants viewed the genocide film. They were then randomly assigned to read one of the two information texts regarding the film and given $5 \mathrm{~min}$ to read it attentively. An experimenter seated in an adjacent control room checked whether participants were reading via a closed-circuit TV system. If they finished reading earlier, they were asked to start over again. After that, the startle paradigm was administered. Participants were instructed to watch a series of pictures, some of which would be neutral, negative, or film related. The instructions specified that, while watching film-related images, participants should think of everything that they had learned during the film and by reading the debriefing. In order to assess engagement in emotion regulation, a state emotion regulation questionnaire was administered immediately following film viewing (i.e., before reading the information text) as well as following the startle paradigm. As well, emotional responses (i.e., PANAS, emotion VAS) were assessed once more following the startle paradigm to explore potential differences in emotional responding after reading the information texts.

\section{Materials and tasks}

Positive and negative information texts. The positive and negative information texts consisted of short articles (approximately 470 words) and contained background information regarding the history of Rwanda related to the presented film fragments. In the positive condition, the text did not aim to downplay the seriousness of the events, but focused on positive aspects, such as that many individuals bravely stood up against the violence, organized rescue missions, or prevented extremists from killing. Furthermore, the text pointed out that the genocide was followed by legal and political investigations and reappraisals both within Rwanda and internationally, reflecting efforts to bring justice to the victims and to prevent similar events from happening in the future. In contrast, the text used in the negative condition repeated and complemented the horrible aspects depicted in the genocide documentary. This included the information that the involved ethnic groups had a long-standing and escalating conflict, resulting in extreme radicalization, hate, and eventually killings. The text further detailed the involvement of virtually all societal levels in the genocide, the inactivity of those who could have intervened, and the horrific numbers of victims who were killed or sexually abused.

Manipulation checks and control questions. To check whether participants in the two conditions differentially engaged in positive reappraisal following film viewing, we used an adapted state version of the Cognitive Emotion Regulation Questionnaire (CERQ; Garnefski, Kraaij, \& Spinhoven, 2002), which had been revised to tap into trauma film responses. The original CERQ is a 36-item scale that measures different cognitive emotion regulation strategies that individuals habitually use when confronted with negative events or situations. Each subscale consists of 4 items presenting a thought in the form of a first-person statement (e.g., positive reappraisal: "I think that I can learn something from the situation"), and requiring respondents to indicate its frequency on a 5-point scale. In our adapted state version, respondents were asked to which degree they had used the specific strategies following exposure to the trauma film on 5-point scales $(1=$ very slightly or not at all, 5 = extremely). For the purpose of this study, we used the positive reappraisal subscale only. At the administration following the startle paradigm (where item variance was the highest), its internal consistency was acceptable $(\alpha=.69)$, albeit somewhat lower than is typical for the respective trait subscale (Garnefski et al., 2002).

A number of control questions were given to the participants at the end of the session to control for prior knowledge of the shown documentary or details of its content. Furthermore, participants were asked to indicate the veracity of three simple statements concerning the content of the debriefing (true, untrue) to reassure good understanding content of the debriefing. One item was true for both debriefing conditions, whereas the other two items were true in one, but not the other debriefing condition. Due to technical failure, these data were lost for two participants. Among all other participants, four $(5.7 \%)$ failed to answer correctly on two of the three simple questions, raising doubts concerning their accurate understanding of the debriefings. Eight individuals indicated that they had known parts of the used trauma film prior to this study, and nine indicated that they had been familiar with details presented in this film. These numbers did not differ between the two conditions, $\chi^{2}$ being $2.3(p=.13)$ and $0.1(p=.72)$, respectively. Excluding participants from the statistical analyses who either failed to answer the control questions correctly, or indicated being familiar with details beforehand, did not change the pattern of results and the conclusions.

Eye-blink startle paradigm. The pictures belonged to one of three categories: 30 reminder pictures from the genocide film, next to 30 neutral control (medium valence, low arousal ratings) and 30 negative control (low valence, high arousal ratings) pictures from the IAPS (Lang et al., 2005). Intensity of the 50-ms white noise startle probes was set at $95 \mathrm{~dB}$.

Data reduction. Startle data from 2 participants (1 in each condition) were lost due to recording failure. Resting EEG data from 1 participant (positive condition) were excluded because only $9 \%$ of 
epochs in the eyes-open condition were artifact free. For all other participants, on average $84.3 \%$ (range $=34-100 ; S D=14.9$ ) of eyes-open and $97.3 \%$ (range $=56-100 ; S D=6.9$ ) of eyes-closed epochs were artifact free. EEG data during film viewing were excluded from the analyses for 1 participant (negative condition), for whom less than $25 \%$ artifact-free epochs could be retained. For all other participants, on average $72.9 \%$ (range $=32-99$; $S D=18.2)$ of all epochs $(N=1,658)$ were artifact free. Thus, data from 71 participants ( 35 in the positive condition) were available for analyses of resting frontal asymmetry, and from 70 (35 in the positive condition) for activation asymmetry.

Statistical analysis. Treatment of extreme cases, transformation of variables with skewed distributions, and the general statistical approach were identical to Study 1. State reappraisal scores were also log-transformed to reduce its strong right-skewed distribution.

\section{Results}

Resting and activation asymmetries. As in Study 1, repeated measures ANOVAs showed no differences between resting and film-viewing frontal asymmetries, and no main or interaction effects involving debriefing condition, all $p s>.10$. As well, frontal activation asymmetry was unrelated to PANAS or VAS change scores, all $r \mathrm{~s}(70)<.12, p \mathrm{~s}>.27$. Again, resting frontal asymmetry scores $(M=0.04, S D=0.09)$ highly correlated with asymmetry scores during film viewing $(M=0.05, S D=0.10), r(70)=.80$, $p<.001$, but not with frontal activation asymmetries $(M=0.01$, $S D=0.06), r=-.13, p=.30$.

Emotional responses. The two debriefing groups did not differ at baseline on any PANAS or emotion VAS subscale, all $t \mathrm{~s}(70)<1$, $p \mathrm{~s}>.35$. A 3 (Time: prefilm, postfilm, end session) $\times 2$ (Condition: positive, negative) repeated measures ANOVA on positive scores revealed a significant main effect of time, $F(2,140)=72.8, p<.001$, $\eta_{\mathrm{p}}^{2}=.51$, whereas no effects involving condition were present, $F \mathrm{~s}<1, p \mathrm{~s}>.68$. Post hoc pairwise comparisons (Bonferroni) showed that positive affect decreased significantly from prefilm to postfilm (Mean change $\left._{\text {c }}=-1.8, S D=4.8\right)$ and decreased further from then to the end of the session (Mean change $=-4.8, S D=4.5), p \mathrm{~s}<.01$. A similar $3 \times 2$ repeated measures ANOVA for negative affect revealed a significant main effect of time, $F(2,140)=47.6, p<.001$, $\eta_{\mathrm{p}}^{2}=.41$, that did not interact with condition, $p=.14$. Pairwise comparisons showed an increase from prefilm to postfilm (Mean change $=5.9, S D=6.1)$, a decrease from then to the end of the session $(M=-3.5, S D=5.3)$, where scores were still significantly elevated with respect to baseline, $p \mathrm{~s}<.001$.

A 4 (Emotion: anxious, shocked, angry, sad) $\times 3$ (Time) $\times 2$ (Condition) repeated measures ANOVA showed a significant Emotion $\times$ Time interaction, $F(6,420)=32.8, p<.001, \varepsilon=.86$, $\eta_{\mathrm{p}}^{2}=.32$, next to main effects of emotion, $F(3,210)=13.9$, $p<.001, \varepsilon=.80, \eta_{\mathrm{p}}^{2}=.17$, and time, $F(2,140)=78.2, p<.001$, $\eta_{\mathrm{p}}^{2}=.53$. There were no main or interaction effects involving condition, $p s>.50$. Pairwise comparisons (Bonferroni) between timings showed that feeling shocked, angry, and sad increased in response to film viewing (Mean $_{\text {change }}=37.8,35.2$, and 28.3, respectively; $S D=30.5,31.1$, and 28.2), then decreased again, yet remained elevated at the end of the session with respect to baseline, all $p \mathrm{~s}<.001$. Scores on feeling anxious were much lower overall $\left(\right.$ Mean $\left._{\text {change }}=5.4, S D=19.3\right)$, yet a comparable pattern was observed, with both postfilm and end-session scores marginally differing from baseline, $p=.047$ and $p=.062$.
Positive reappraisal following the debriefings. To test whether the two debriefing conditions affected the use of positive reappraisal in the period following film viewing, positive reappraisal scores of the state CERQ subscales at the end of the sessions were entered as dependent variables in an analysis of covariance (ANCOVA), using condition as independent variable and CERQ score prior to reading the positive or information as covariate. The covariate was a significant predictor, $F_{\mathrm{S}}(1,69)=44.5, p<.001, \eta_{\mathrm{p}}^{2}=.39$, and, as intended, condition significantly affected positive reappraisal, $F(1,69)=5.3, p=.024$, $\eta_{\mathrm{p}}^{2}=.07$, with a larger increase following the positive information $\left(M_{\text {pre }}=6.2, S D=1.8 ; M_{\text {post }}=6.8, S D=2.3\right)$ than following the negative information $\left(M_{\text {pre }}=6.5, S D=1.9 ; M_{\text {post }}=6.1, S D=2.3\right)$, $t(70)=2.5, p=.016$.

Condition effects and time course of startle potentiation. A 2 (Category: reminder, negative) $\times 3$ (Probe Timing: $2.5,4.5,7 \mathrm{~s}) \times$ 2 (Debriefing Condition: positive, negative) repeated measures ANOVA on startle potentiation scores revealed no significant threeway interaction, $F(2,136)<1, p=.57$. However, there was a significant Probe Timing $\times$ Condition interaction, $F(2,136)=3.9$, $p=.022, \eta_{\mathrm{p}}^{2}=.06$, next to a main effects for category, $F(1,68)=18.9, p<.001, \eta_{\mathrm{p}}^{2}=.22$, indicating that startle potentiation scores were significantly larger in negative compared to reminder pictures. Follow-up analyses revealed that, in the positive debriefing condition, only category significantly modulated startle potentiation, $F(1,34)=19.8, p<.001, \eta_{\mathrm{p}}^{2}=.37$, with higher scores for negative, compared to reminder trials. In the negative debriefing condition, the effect of category was reduced to trend-significant level, $F(1,34)=3.7, p=.064, \eta_{\mathrm{p}}^{2}=.10$, and a significant main effect of time emerged, $F(2,68)=5.6, p=.006, \eta_{\mathrm{p}}^{2}=.14$. Pairwise comparisons (Bonferroni) on estimated marginal means in this condition show that potentiation scores at the 4.5-s timing were higher than at the 2.5-s timing, $p=.012$, and also tended to be higher than at the 7-s timing, $p=.091$, irrespective of category.

Frontal asymmetry effects on startle potentiation ${ }^{2}$. For resting frontal asymmetry effects on startle potentiation after reminder picture offset, a regression model $(d f=3,65)$ showed no significant moderation by debriefing condition, $p=.70$. Correlation analyses in the entire sample revealed a significant positive correlation between resting frontal asymmetry and startle potentiation, $r(69)=.33, p=.005$, with more left-sided frontal activity predicting higher startle potentiation after reminder picture offset. For activation asymmetry as a predictor, the regression model $(d f=3,64)$ similarly revealed a nonsignificant interaction term, $p=.50$. Unlike for resting asymmetry, it did not correlate significantly across the entire sample with startle potentiation after reminder picture offset, $r(68)=-.02, p=.89$ (see Figure 6). In order to determine whether resting frontal asymmetry predicted startle potentiation over and above emotional responses to the trauma film, we included anger and sadness increase as predictors, followed by frontal asymmetry. This second step significantly enhanced the model, $R_{\text {change }}^{2}=.06, F(1,65)=4.9, p=.03$, resting

2. PANAS and emotion VAS change scores, as well as positive reappraisal scores, were unrelated to reminder startle potentiation, largest $r=-.19, p=.11$, and are therefore omitted from the following analyses. However, we considered anger and sadness increase scores in the following models, as they correlated positively with startle potentiation scores at the 7 -s timing for reminder trials, $r=.33, p<.01$, and $r=.27, p=.03$. 


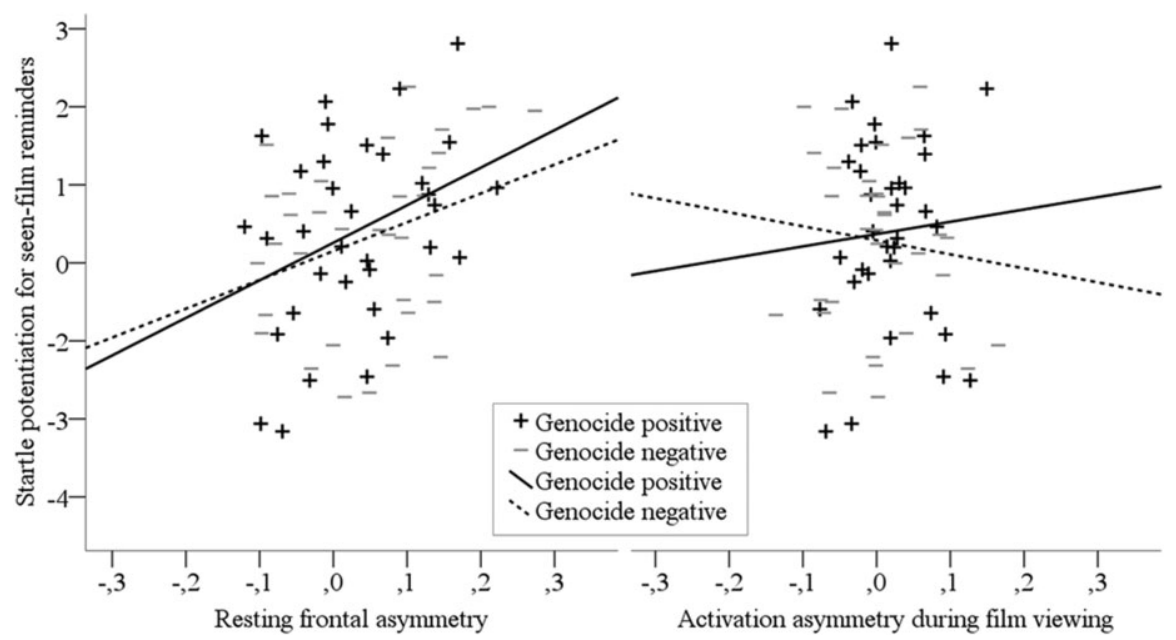

Figure 6. Scatter plots depicting frontal asymmetry at rest (left; $N=69)$ and activation asymmetry during film viewing (right; $N=68)$ as predictors of startle potentiation at $7 \mathrm{~s}$ (1-s poststimulus offset) for film reminders. Both interactions involving information condition are not significant. Across groups, resting frontal asymmetry positively predicted reminder startle potentiation, whereas no significant associations emerged with activation asymmetry.

frontal asymmetry being a significant predictor, $\beta=.26, t=2.2$, $p=.03$.

Further exploratory analyses revealed no interaction effects or correlations for startle potentiation at the other probe timings or after unrelated negative picture offset involving frontal resting, $r \mathrm{~s}(69)<.08, p \mathrm{~s}>.55$, or activation asymmetry, $r \mathrm{~s}(68)<.18$, $p s>.15$. For parietal asymmetry at rest, we found an interaction at trend level $(p=.05)$, but no significant correlations in both debriefing groups, $p s>.13$. For parietal activation asymmetry, there was no significant interaction, $p>.34$, and no significant zero-order correlation, $p=.07$.

\section{Summary and Comparison with Study 1}

The results indicate that, as intended, the positive information condition facilitated the use of reappraisal compared to the negative information condition. Yet, this appeared to have no effect on emotional responding. Regarding the effects of frontal asymmetry on physiological self-regulation in response to trauma film reminders, condition did not play a moderating role. However, we now found that more left-sided frontal activity at rest predicted higher startle potentiation after reminder picture offset (i.e., worse physiological self-regulation) in both conditions, over and above increases in feeling angry and sad due to film viewing that were similarly related to startle. Meanwhile, frontal activation asymmetry was unrelated to startle outcomes. Furthermore, we found no relationship between frontal asymmetry and startle potentiation after the offset of unrelated negative pictures, which appears to be at odds with previous findings by Jackson et al. (2003). One explanation could be that affective processing in negative images was not independent from processing reminder images. This interpretation seems to be supported by our finding that the time course of startle potentiation was modulated by debriefing condition in the absence of an interaction with stimulus category. That is, in the context of our startle paradigm, unrelated negative pictures may also have activated thoughts about the previously seen trauma film, which may have impeded emotion regulation in response to these pictures.

The finding that in Study 1 frontal activation asymmetry, but not resting asymmetry, predicted startle regulation (differently for the two trauma films) appears to be at odds with the finding in Study 2 that resting frontal asymmetry, but not activation asymmetry, predicted startle regulation. Since resting frontal asymmetry may be susceptible for confounding by transient motivational factors (Coan et al., 2006), we explored the possibility that resting asymmetry reflected a state of subtle emotional provocation in Study 2, but not in Study 1. We thus compared baseline (i.e., prefilm) affective states between the two studies and explored their influence on the resting measurement of frontal asymmetry. Baseline positive and negative affect levels did not differ between the two studies, $t \mathrm{~s}(134)<1, p \mathrm{~s}>.41$. Likewise, a 4 (Emotion) $\times 2$ (Study) repeated measures ANOVA on baseline emotion VAS scores yielded no significant main or interaction effects involving study, all $p \mathrm{~s}>.13$. Also, resting frontal asymmetry levels were similar in both studies, $t(131)=1.1, p=.28$. In Study 1 , resting frontal asymmetry did not correlate with any of the baseline indices of current emotion, all $r \mathrm{~s}(62)<.18, p \mathrm{~s}>.18$. Only in Study 2, more left-sided frontal activity at rest tended to correlate with lower baseline anxiety levels, $r(71)=-.23, p=.06$.

\section{Discussion}

\section{Type of Trauma Film Moderates the Effects}

Across two studies, the most salient observation is that frontal asymmetry appears to have distinct effects on physiological selfregulation in the activation of aversive memories, depending on the type of aversive material used. While more left-sided frontal activity or activation was hypothesized to predict dampened startle responses after reminder picture offset, this was only the case for reminders of a film depicting a staged road accident. In contrast, for reminders of a genocide documentary, left-sided activation during film viewing tended to predict stronger, rather than dampened, startle responses in Study 1, and we found a similar and significant effect for left-sided resting activity in Study 2. Thus, our findings indicate that frontal asymmetry at rest and during provocation can be associated with both enhanced and impaired physiological selfregulation. Notably, the positive and negative correlations were in the .30-.50 range and, thus, comparable in size to the effects reported by Jackson et al. (2003). These authors found that left- 
sided frontal activity at rest predicted lower startle potentiation after negative picture offset. Furthermore, and in line with the view that frontal asymmetry indexes individual differences in automatic emotion regulation (Jackson et al., 2003; Parvaz et al., 2012), its effects manifested specifically after reminder picture offset, whereas it did not significantly predict physiological responses during picture presentation. As well, our data show that these effects were specific to the anterior electrode pairs, and were not present in parietal electrodes.

What might account for the differential effects of frontal asymmetry and activation in the two film conditions? An appealing interpretation is that differences in content-related cognitive processes may have resulted in different consequences of attempts to regulate emotions. Compared to the road accident film, emotion regulation in the genocide film may have required a higher amount of cognitive resources, which is thought to have deleterious consequences for physiological responding (Gross \& John, 2003). This might explain why we found a link between more left-sided frontal activity and higher responding to film reminders. Study 2 aimed to explore the role of one such process, namely, positive reappraisal, by which individuals alter the emotional impact of a stressor by attaching a positive meaning (Garnefski et al., 2002). Although we succeeded in manipulating positive reappraisal by providing positive and negative information, this had no effect on the association between frontal asymmetry and physiological responding. These findings could indicate that reappraisal is not the crucial moderator that we tried to identify.

However, it would be premature to rule out this possibility. Importantly, providing positive information that people can use for positive reappraisal may have been a relatively weak intervention. As a consequence, even in the positive condition, participants may still have been unable to engage in positive reappraisal successfully. This view is supported by the absence of condition differences in emotional recovery following film viewing. It is therefore possible that participants in the positive debriefing condition of Study 2 used positive reappraisal still to a very little extent, especially when compared with our participants in the road accident condition of Study 1. Since we did not collect data regarding emotion regulation in Study 1, this issue remains to be investigated further. Future studies might thus want to use emotional material in which reappraisal is easier to influence, or use stronger manipulations, such as directly challenging participants' cognitive and emotional reactions (e.g., Takarangi \& Strange, 2010).

Furthermore, there may be differences between the films that were not measured in this study. For instance, the used road accident film had a positive educational message that participants can integrate with their prior knowledge about road safety. In contrast, the genocide film consisted of real-life footage aiming to inform and educate about a historical humanitarian and political tragedy. It is very unlikely that our (Western European) participants were directly confronted with the horrors of genocide, and they may encounter difficulties in integrating this content with existing knowledge and prior beliefs. Notably, such difficulties are thought to exacerbate the risk of developing psychopathology after trauma (Ehlers \& Clark, 2000; Janoff-Bulman, 1992), and could provide an alternative account for why left-sided frontal activity was associated with exaggerated startle responding in Study 2.

\section{Effects of Resting and State-Dependent Frontal Asymmetry}

Another salient observation in the present studies is that physiological self-regulation could be predicted by resting frontal asym- metry in Study 2, whereas frontal activation asymmetry during film viewing was predictive in Study 1. This finding is surprising, since the measurement of resting and film-related frontal asymmetry were kept similar in both studies. A possible explanation is related to the idea that individual differences in frontal asymmetry may only be predictive of emotional outcomes if they are measured in a relevant motivational context. For example, frontal asymmetry correlates with negative affectivity when measured in a fearful state (Coan et al., 2006) or with trait approach motivation when measured in a state of sexual attraction (Wacker, Mueller, Pizzagalli, Hennig, \& Stemmler, 2013). According to this view, our resting state measurements can be considered as an uncontrolled motivational context, which may have been relevant for the later responses to the trauma films (e.g., anticipatory anxiety, nervousness) or not (e.g., curiosity, feeling bored). If the resting state reflected such a "relevant" emotional context for many participants in Study 2, but not in Study 1, then this would explain why resting asymmetry predicted physiological self-regulation in reminder pictures in Study 2, but not in Study 1. Consequently, change in frontal asymmetry during film viewing may have been more relevant to emotional responding in Study 1, compared to Study 2.

Note that this explanation remains speculative, since our data do not provide compelling indications that the resting state measurements were differentially influenced by emotional states. That is, we found no robust differences in baseline motivational states or in asymmetry scores. Also, there were only weak indications (i.e., a relatively small trend) that prefilm anxiety may have led to reduced left-sided resting activity in Study 2 only. Thus, with the present data, we can only conclude that frontal asymmetry measured at rest and during provocation can both be informative about individual differences in responding to trauma film reminders. This confirms the utility of including both baseline measurements and standardized provocations to capture relevant individual differences in frontal asymmetry.

One of the practical questions raised in this article was whether frontal asymmetry could serve to predict resilient responding at a later point in time. While our models including resting frontal asymmetry provide direct evidence for answering this question, the models including film-induced activation asymmetry must be interpreted with more caution. On the one hand, activation asymmetry can be conceptualized as tapping the individual's traitlike capability of emotional responding, and thus would be thought to moderate later physiological responses. On the other hand, our measurement of activation asymmetry is intrinsically linked with responding to the trauma film, and may thus itself reflect a (mal)adaptive process that mediates later physiological responses (see Figure 2, panel B). Our findings favor the moderation over the mediation model, since frontal asymmetry was not systematically affected by film viewing and did not correlate with subjective indices of emotional responding to the film. Of note, in light of the unexpected moderation by film condition in Study 1, it is possible that a small mediation effect occurred in the road accident clip only, which may have gone undetected due to a lack of power. Thus, to disentangle these interpretations more conclusively, future studies would need to include a separate emotional provocation before trauma film viewing and test whether prefilm and perifilm activation asymmetries display patterns similar to those found here.

\section{Limitations}

There are some caveats to interpretation of the present data that deserve to be mentioned. First, in Study 1, the victims in the two 
trauma films differed in ethnicity, which might have lead to stronger in-group empathy, and hence emotional responding in the road accident condition (Brown, Bradley, \& Lang, 2006). This might provide an alternative account for differential effects in the two film conditions. However, in both films, we clearly observed that the used films produced the intended subjective responses, including a reduction in positive affect paralleled by increases in negative affect, as well as increased VAS scores on feeling shocked, angry, and sad. All of these effects were more pronounced in the genocide film than the road accident film, which makes in-group empathy an unlikely confounding factor in the present data. Second, and conversely, higher mean emotionality in the genocide condition may have led to a greater need for emotion regulation in this condition. Likewise, across participants, our data from Study 1 suggest enhanced responding to seen-film reminder pictures (compared to unseen-film reminders) only in the genocide film condition. However, it appears plausible that these condition effects are the result, rather than the antecedent, of differences in emotion regulation processes. The absence of heightened startle potentiation in the road accident condition can be interpreted in terms of successful physiological downregulation. Third, our findings may be limited by the parameters and stimuli that we used in our startle paradigm. For instance, we assessed physiological self-regulation using startle probes $1 \mathrm{~s}$ after stimulus offset. Research indicates that this timing is well suited to capture sustained affective processing after picture offset (Hajcak \& Olvet, 2008), and modulation of physiological responses by emotion regulation can occur even faster, in the range of several hundred milliseconds (e.g., Blechert, Sheppes, Di Tella, Williams, \& Gross, 2012). Still, our data are not informative regarding regulatory effects that may manifest themselves in the range of minutes, hours, and longer. Another concern may be that, in Study 2, startle potentiation was lower in film reminders compared to unrelated negative images. Although this is not surprising, it also indicates that the responses to trauma film memories may not be comparable to those seen in traumatized individuals, for whom trauma memories can be highly distressing. Finally, a related concern is that our results are limited by the use of a rather homogenous, high-functioning student sample in that they may not translate directly to clinical populations.

\section{Conclusion}

We investigated whether indices of frontal EEG asymmetry can serve as a predictor of physiological responding to aversive memories. This was done by subjecting participants to a trauma film paradigm and administering a startle paradigm in which they viewed reminder images from the film they had seen. Both resting frontal asymmetry and frontal activation asymmetry in response to film viewing served as predictors of startle responses. Our results suggest that relatively left-sided frontal activity at rest and activation during viewing of an aversive film can reveal individual differences in the processing of aversive memories, but they can be predictive of enhanced as well as of impaired physiological selfregulation, depending on the type of trauma film that is used. We found no indication that engagement in positive reappraisal is responsible for these differential effects, but future studies are clearly needed to further explore this possibility. Furthermore, our findings call for a systematic investigation of other potential moderators in the effects of frontal asymmetry, such as the availability of contextual information, prior knowledge, beliefs, and schemas. Eventually, this might contribute to our understanding of individual risk and resilience factors and their differential involvement in different types of traumatic experience (e.g., Grimm, Hulse, Preiss, \& Schmidt, 2012; McNally \& Robinaugh, 2011).

\section{References}

Allen, J. J. B., Coan, J. A., \& Nazarian, M. (2004). Issues and assumptions on the road from raw signals to metrics of frontal EEG asymmetry in emotion. Biological Psychology, 67, 183-218. doi: 10.1016/ j.biopsycho.2004.03.007

Allen, J. J. B., \& Kline, J. P. (2004). Frontal EEG asymmetry, emotion, and psychopathology: The first, and the next 25 years. Biological Psychology, 67, 1-5. doi: 10.1016/j.biopsycho.2004. 03.001

American Electroencephalographic Society. (1994). Guideline thirteen: Guidelines for standard electrode position nomenclature. Journal of Clinical Neurophysiology, 11, 111-113.

Blechert, J., Sheppes, G., Di Tella, C., Williams, H., \& Gross, J. J. (2012). See what you think: Reappraisal modulates behavioral and neural responses to social stimuli. Psychological Science, 23, 346-353. doi: 10.1177/0956797612438559

Blumenthal, T. D., Cuthbert, B. N., Filion, D. L., Hackley, S., Lipp, O. V., \& Van Boxtel, A. (2005). Committee report: Guidelines for human startle eyeblink electromyographic studies. Psychophysiology, 42, 1-15. doi: 10.1111/j.1469-8986.2005.00271.x

Boden, M. T., Westermann, S., McRae, K., Kuo, J., Alvarez, J., Kulkarni, M. R., .. . Bonn-Miller, M. O. (2013). Emotion regulation and posttraumatic stress disorder: A prospective investigation. Journal of Social and Clinical Psychology, 32, 296-314.

Bonanno, G. A. (2004). Loss, trauma, and human resilience-Have we underestimated the human capacity to thrive after extremely aversive events? American Psychologist, 59, 20-28. doi: 10.1037/0003066x.59.1.20

Brewin, C. R., Gregory, J. D., Lipton, M., \& Burgess, N. (2010). Intrusive images in psychological disorders: Characteristics, neural mechanisms, and treatment implications. Psychological Review, 117, 210-232. doi: $10.1037 / \mathrm{a} 0018113$
Brown, L. M., Bradley, M. M., \& Lang, P. J. (2006). Affective reactions to pictures of ingroup and outgroup members. Biological Psychology, 71, 303-311. doi: 10.1016/j.biopsycho.2005.06.003

Coan, J. A., \& Allen, J. J. B. (2004). Frontal EEG asymmetry as a moderator and mediator of emotion. Biological Psychology, 67, 7-49. doi: 10.1016/j.biopsycho.2004.03.002

Coan, J. A., Allen, J. J. B., \& McKnight, P. E. (2006). A capability model of individual differences in frontal EEG asymmetry. Biological Psychology, 72, 198-207. doi: 10.1016/j.biopsycho.2005.10.003

Davidson, R. J. (1998). Affective style and affective disorders: Perspectives from affective neuroscience. Cognition \& Emotion, 12, 307-330.

Davis, M., Walker, D. L., \& Lee, Y. L. (1997). Roles of the amygdala and bed nucleus of the stria terminalis in fear and anxiety measured with the acoustic startle reflex-Possible relevance to PTSD. Annals of the New York Academy of Sciences, 821, 305-331. doi: 10.1111/j.17496632.1997.tb48289.x

Ehlers, A., \& Clark, D. M. (2000). A cognitive model of posttraumatic stress disorder. Behaviour Research and Therapy, 38, 319-345. doi: 10.1016/S0005-7967(99)00123-0

Garnefski, N., Kraaij, V., \& Spinhoven, P. (2002). Manual for the use of the Cognitive Emotion Regulation Questionnaire. Leiderdorp, The Netherlands: DATEC.

Goldsmith, H. H., \& Davidson, R. J. (2004). Disambiguating the components of emotion regulation. Child Development, 75, 361-365.

Goodman, R. N., Rietschel, J. C., Lo, L.-C., Costanzo, M. E., \& Hatfield, B. D. (2013). Stress, emotion regulation and cognitive performance: The predictive contributions of trait and state relative frontal EEG alpha asymmetry. International Journal of Psychophysiology, 87, 115-123. doi: 10.1016/j.ijpsycho.2012.09.008

Grimm, A., Hulse, L., Preiss, M., \& Schmidt, S. (2012). Post- and peritraumatic stress in disaster survivors: An explorative study about the 
influence of individual and event characteristics across different types of disasters. European Journal of Psychotraumatology, 3. doi: 10.3402/ ejpt.v3i0.7382

Gross, J. J., \& John, O. P. (2003). Individual differences in two emotion regulation processes: Implications for affect, relationships, and wellbeing. Journal of Personality and Social Psychology, 85, 348-362. doi: 10.1037/0022-3514.85.2.348

Hajcak, G., \& Olvet, D. M. (2008). The persistence of attention to emotion: Brain potentials during and after picture presentation. Emotion, 8, 250255. doi: 10.1037/1528-3542.8.2.250

Harmon-Jones, E., Gable, P. A., \& Peterson, C. K. (2010). The role of asymmetric frontal cortical activity in emotion-related phenomena: A review and update. Biological Psychology, 84, 451-462.

Heller, W. (1993). Neuropsychological mechanisms of individual differences in emotion, personality, and arousal. Neuropsychology, 7, 476489.

Holmes, E. A., \& Bourne, C. (2008). Inducing and modulating intrusive emotional memories: A review of the trauma film paradigm. Acta Psychologica, 127, 553-566. doi: 10.1016/j.actpsy.2007.11.002

Holmes, E. A., James, E. L., Coode-Bate, T., \& Deeprose, C. (2009). Can playing the computer game "Tetris" reduce the build-up of flashbacks for trauma? A proposal from cognitive science. Plos ONE, 4, 6. doi: e415310.1371/journal.pone.0004153

Jackson, D. C., Mueller, C. J., Dolski, I., Dalton, K. M., Nitschke, J. B., Urry, H. L., . . Davidson, R. J. (2003). Now you feel it, now you don't: Frontal brain electrical asymmetry and individual differences in emotion regulation. Psychological Science, 14, 612-617.

Janoff-Bulman, R. (1992). Shattered assumptions: Toward a new psychology of trauma. New York, NY: The Free Press.

Keil, A., Debener, S., Gratton, G., Junghöfer, M., Kappenman, E. S., Luck, S. J., ... Yee, C. M. (2013). Committee report: Publication guidelines and recommendations for studies using electroencephalography and magnetoencephalography. Psychophysiology, 51, 1-21. doi: 10.1111/ psyp. 12147

Koslov, K., Mendes, W. B., Pajtas, P. E., \& Pizzagalli, D. A. (2011). Asymmetry in resting intracortical activity as a buffer to social threat. Psychological Science, 22, 641-649. doi: 10.1177/0956797611403156

Lang, P. J., Bradley, M. M., \& Cuthbert, B. N. (2005). International Affective Picture System (IAPS): Instruction manual and affective ratings. Technical report A-6. Gainesville, FL: University of Florida.

Lopez-Duran, N. L., Nusslock, R., George, C., \& Kovacs, M. (2012). Frontal EEG asymmetry moderates the effects of stressful life events on internalizing symptoms in children at familial risk for depression. Psychophysiology, 49, 510-521. doi: 10.1111/j.1469-8986.2011. 01332.x

McNally, R. J., \& Robinaugh, D. J. (2011). Risk factors and posttraumatic stress disorder: Are they especially predictive following exposure to less severe stressors? Depression and Anxiety, 28, 1091-1096. doi: 10.1002/ da. 20867

Meyer, T., Smeets, T., Giesbrecht, T., \& Merckelbach, H. (2012). The efficiency of reappraisal and expressive suppression in regulating everyday affective experiences. Psychiatry Research, 200, 964-969. doi: 10.1016/j.psychres.2012.05.034

Meyer, T., Smeets, T., Giesbrecht, T., Quaedflieg, C. E. M., Girardelli, M., Mackay, G. N., \& Merckelbach, H. (2013). Individual differences in spatial configuration learning predict the occurrence of intrusive memories. Cognitive, Affective, \& Behavioral Neuroscience, 13, 186-196. doi: 10.3758/s13415-012-0123-9

Miller, G. A., Crocker, L. D., Spielberg, J. M., Infantolino, Z. P., \& Heller, W. (2013). Issues in localization of brain function: The case of lateralized frontal cortex in cognition, emotion, and psychopathology. Frontiers in Integrative Neuroscience, 7. doi: 10.3389/fnint.2013.00002

Nusslock, R., Shackman, A. J., Harmon-Jones, E., Alloy, L. B., Coan, J. A., \& Abramson, L. Y. (2011). Cognitive vulnerability and frontal brain asymmetry: Common predictors of first prospective depressive episode. Journal of Abnormal Psychology, 120, 497-503. doi: 10.1037/ a0022940

Orr, S. P., \& Roth, W. T. (2000). Psychophysiological assessment: Clinical applications for PTSD. Journal of Affective Disorders, 61, 225-240.

Ozer, E. J., Best, S. R., Lipsey, T. L., \& Weiss, D. S. (2003). Predictors of posttraumatic stress disorder and symptoms in adults: A meta-analysis. Psychological Bulletin, 129, 52-73. doi: 10.1037//0033-2909.129.1.52

Parvaz, M., MacNamara, A., Goldstein, R., \& Hajcak, G. (2012). Eventrelated induced frontal alpha as a marker of lateral prefrontal cortex activation during cognitive reappraisal. Cognitive, Affective, \& Behavioral Neuroscience, 12, 730-740. doi: 10.3758/s13415-0120107-9

Pfurtscheller, G., Stancak, A., \& Neuper, C. (1996). Event-related synchronization (ERS) in the alpha band-An electrophysiological correlate of cortical idling: A review. International Journal of Psychophysiology, 24, 39-46. doi: 10.1016/s0167-8760(96)00066-9

Pivik, R. T., Broughton, R. J., Coppola, R., Davidson, R. J., Fox, N., \& Nuwer, M. R. (1993). Guidelines for the recording and quantitative analysis of electroencephalographic activity in research contexts. Psychophysiology, 30, 547-558. doi: 10.1111/j.1469-8986.1993. tb02081.x

Rivest, L. P. (1994). Statistical properties of Winsorized means for skewed distributions. Biometrika, 81, 373-383. doi: 10.1093/biomet/81.2.373

Takarangi, M. K. T., \& Strange, D. (2010). Emotional impact feedback changes how we remember negative autobiographical experiences. Experimental Psychology, 57, 354-359. doi: 10.1027/1618-3169/ a000042

Thibodeau, R., Jorgensen, R. S., \& Kim, S. (2006). Depression, anxiety, and resting frontal EEG asymmetry: A meta-analytic review. Journal of Abnormal Psychology, 115, 715-729. doi: 10.1037/0021843x.115.4.715

Tomarken, A. J., Davidson, R. J., Wheeler, R. E., \& Doss, R. C. (1992). Individual differences in anterior brain asymmetry and fundamental dimensions of emotion. Journal of Personality and Social Psychology, 62, 676-687.

Tomarken, A. J., Davidson, R. J., Wheeler, R. E., \& Kinney, L. (1992), Psychometric properties of resting anterior EEG asymmetry: Temporal stability and internal consistency. Psychophysiology, 29, 576-592.

Towers, D. N., \& Allen, J. J. B. (2009). A better estimate of the internal consistency reliability of frontal EEG asymmetry scores. Psychophysiology, 46, 132-142. doi: 10.1111/j.1469-8986.2008. 00759.x

Velo, J. R., Stewart, J. L., Hasler, B. P., Towers, D. N., \& Allen, J. J. B. (2012). Should it matter when we record? Time of year and time of day as factors influencing frontal EEG asymmetry. Biological Psychology, 91, 283-291.

Wacker, J., Mueller, E. M., Pizzagalli, D. A., Hennig, J. R., \& Stemmler, G. (2013). Dopamine-D2-receptor blockade reverses the association between trait approach motivation and frontal asymmetry in an approach-motivation context. Psychological Science, 24, 489-497. doi: 10.1177/0956797612458935

Watson, D., Clark, L. A., \& Tellegen, A. (1988). Development and validation of brief measures of positive and negative affect: The PANAS scales. Journal of Personality and Social Psychology, 54, 10631070.

Weidmann, A., Conradi, A., Grögera, K., Fehma, L., \& Fydrich, T. (2009). Using stressful films to analyze risk factors for PTSD in analogue experimental studies-Which film works best? Anxiety, Stress \& Coping, 22, 549-569.

(ReceIved September 5, 2013; AccePted April 3, 2014) 